\title{
Random regression models for the estimation of genetic and environmental covariance functions for growth traits in Santa Ines sheep
}

\author{
J.L.R. Sarmento ${ }^{1}$, R.A. Torres ${ }^{2}$, W.H. Sousa ${ }^{3}$, R.N.B. Lôbo ${ }^{4}$,

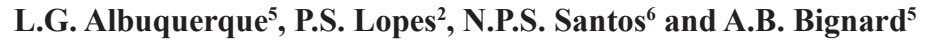 \\ ${ }^{1}$ Departamento de Zootecnia, Universidade Federal do Piauí, \\ Teresina, PI, Brasil \\ ${ }^{2}$ Departamento de Zootecnia, Universidade Federal de Viçosa, \\ Viçosa, MG, Brasil \\ ${ }^{3}$ Empresa Estadual de Pesquisa Agropecuária da Paraíba S.A, \\ João Pessoa, PB, Brasil \\ ${ }^{4}$ Empresa Brasileira de Pesquisa Agropecuária - EMBRAPA Caprinos, \\ Sobral, CE, Brasil \\ ${ }^{5}$ Departamento de Zootecnia, Faculdade de Ciências Agrárias e Veterinárias, \\ Universidade Estadual Paulista, Jaboticabal, SP, Brasil \\ ${ }^{6}$ Departamento de Agronomia, Universidade Federal do Piauí, \\ Campus Professora Cinobelina Elvas, Bom Jesus, PI, Brasil \\ Corresponding author: J.L.R. Sarmento \\ E-mail: sarmento@ufpi.edu.br
}

Genet. Mol. Res. 15 (2): gmr.15025749

Received November 6, 2015

Accepted April 10, 2016

Published June 21, 2016

DOI http://dx.doi.org/10.4238/gmr.15025749

\begin{abstract}
Polynomial functions of different orders were used to model random effects associated with weight of Santa Ines sheep from birth to 196 days. Fixed effects included in the models were contemporary groups, age of ewe at lambing, and fourth-order Legendre polynomials for age to represent the average growth curve. In the random part, functions of different orders were included to model variances associated with direct additive and maternal genetic effects
\end{abstract}


and with permanent environmental effects of the animal and mother. Residual variance was fitted by a sixth-order ordinary polynomial for age. The higher the order of the functions, the better the model fit the data. According to the Akaike information criterion and likelihood ratio test, a continuous function of order, five, five, seven, and three for direct additive genetic, maternal genetic, animal permanent environmental, and maternal permanent environmental effects $(\mathrm{k}=5573)$, respectively, was sufficient to model changes in (co)variances with age. However, a more parsimonious model of order three, three, five, and three $(\mathrm{k}=3353)$ was suggested based on Schwarz's Bayesian information criterion for the same effects. Since it was a more flexible model, model $k=5573$ provided inconsistent genetic parameter estimates when compared to the biologically expected result. Predicted breeding values obtained with models $\mathrm{k}=3353$ and $\mathrm{k}=5573$ differed, especially at young ages. Model $\mathrm{k}=3353$ adequately fit changes in variances and covariances with time, and may be used to describe changes in variances with age in the Santa Ines sheep studied.

Key words: Covariance function; Genetic correlation; Growth traits; Legendre polynomials; Santa Inês sheep

\section{INTRODUCTION}

A multi-trait model can be defined as a model of finite dimension in which a continuous scale is arbitrarily divided into intervals (Meyer, 1998b) and only some points along the growth curve are measured. The use of methods that can incorporate the entire information of an animal, permit a more precise estimation of environmental factors, and allow the use of observed instead of estimated data to increase accuracy and permit selection and genetic breeding is a powerful strategy.

In this respect, Henderson (1982) proposed the use of models that employ regression coefficients treated as random. These models are currently called random regression models. When fitting a random regression model, implicitly, a continuous function that enables the description of genetic and environmental changes over time is fitted. Several studies have employed orthogonal Legendre polynomials as continuous functions, which may require different orders of fit for each random effect present in the analysis model. The lack of an appropriate model, i.e., the lack of knowledge of the most appropriate order of fit for the function used, may erroneously influence the partitioning of phenotypic variance into its genetic and environmental components.

Lack of an appropriate model, i.e., the unknown order setting most appropriate to the function employed, the partition, could erroneously influence phenotypic variances due to the effects in the model. In meat sheep, studies have been conducted to evaluate the order of fit required for continuous functions applied to random regression models, as developed by Lewis and Brotherstone (2002), Fischer et al. (2004), Sarmento et al. (2006a), Molina et al. (2007), and Sarmento et al. (2010), and these differ in the order of fit of the functions adopted.

The objective of the present work was to estimate genetic covariance functions for growth of Santa Ines sheep using random regression models. 


\section{MATERIAL AND METHODS}

A total of 17,767 weight records were used, which were measured at different ages from 4210 lambs born to 130 sire and 1552 dams belonging to three experimental Santa Ines sheep flocks of the Paraíba State Company of Agricultural Research (EMEPA-PB) and the Brazilian Agricultural Research Company (EMBRAPA Caprinos and EMBRAPA Tabuleiros Costeiros).

Data from single- and multiple-born lambs weighed until 196 days of age, whose mean daily weight was within the average of all animals of the same contemporary group \pm three standard deviations and which belonged to contemporary groups with at least five animals, were considered for analysis. Contemporary group was defined by flock, year and season of weighing, lamb sex, type of birth, and age class of animal. Two seasons of weighing were defined: rainy season (March to July) and dry season (August to February).

Age classes, divided at intervals of 28 days for eight classes, were included in the contemporary groups, as suggested by Meyer (2005), to reduce the amplitude of ages of animals that were compared directly within each group. This decision was on the basis of the observation in previous studies of a broad amplitude of ages within contemporary groups formed by excluding age classes, which directly resulted in an exacerbated increase of phenotype variance.

Since age ranged from birth to 196 days, with weight records obtained at average intervals of 28 days, the number of animals at some ages was small. Thus, to increase the number of animals at each age, after 112 days, age of animals was divided into 3-day intervals, for a total of 151 age classes, including birth. In all, 5537 animals were used in the relationship matrix.

Orthogonal Legendre polynomials for age were used as continuous functions to represent fixed and random regressions. The models fitted by different-order functions for random effects can generally be described as follows:

$y_{i j}=F+\sum_{m=1}^{4} \beta_{m} \phi_{m}+\sum_{m=1}^{k_{a}-1} \alpha_{i m} \phi_{m}+\sum_{m=1}^{k_{e}-1} \rho_{i m} \phi_{m}+\sum_{m=1}^{k_{m}-1} \gamma_{i m} \phi_{m}+\sum_{m=1}^{k g-1} \delta_{i m} \phi_{m}+\varepsilon_{i j}$ (Equation 1)

where, $y_{i j}$ is weight on the $j^{\text {th }}$ day of lamb $i ; F$ refers to a set of fixed effects consisting of contemporary group (1112 subclasses) and the covariate age of ewe at lambing (linear and quadratic effects); $\beta_{m}$ is the $m^{\text {th }}$ fixed regression coefficient for weight over the Legendre polynomial represented by a cubic function to model the average growth curve of the population, which was determined in a previous study (Sarmento et al., 2011); $\alpha_{i m}, \gamma_{i m}$, $\delta_{i m}$, and $\rho_{i m}$ are direct additive genetic, maternal additive genetic, maternal permanent environmental, and animal permanent environmental regression coefficients, respectively, for lamb $i ; k_{a}, k_{m}, k_{q}$, and $k_{c}$ are the orders of fit of the corresponding Legendre polynomials, ranging from two to seven, which were used to determine the most appropriate order for each random effect; $\phi_{m}$ is the $m^{\text {th }}$ Legendre polynomial function for standardized age $(-1<$ age $<1$ ); and $\varepsilon_{i j}$ is the residual random effect.

Residual variance was considered to be heterogeneous using a variance function fitted by a sixth-order ordinary polynomial as described by Sarmento et al. (2010), which can be represented as follows: 


$$
\sigma_{j}^{2}=\sigma_{0}^{2}\left(1+\sum_{r=1}^{6} \beta_{r}\left(\alpha_{i j}^{*}\right)^{r}\right)
$$

where, $\sigma_{j}^{2}$ is the residual variance at $j^{\text {th }}$ age; $\sigma_{0}^{2}$ is the variance of the intercept; $\beta_{r}$ is the regression coefficient of the variance function; and $\alpha_{i j}^{*}$ is the age at measurement.

The matrix presentation of the above model with its respective presumptions is:

$$
\begin{gathered}
y=X b+Z_{l} a+Z_{2} c+Z_{3} m+Z_{4} q+e \\
E\left[\begin{array}{l}
y \\
a \\
c \\
m \\
q \\
e
\end{array}\right]=\left[\begin{array}{l}
X b \\
0 \\
0 \\
0 \\
0 \\
0
\end{array}\right], \begin{array}{l}
\operatorname{Var}(a)=K_{a} \otimes A \\
\operatorname{Var}(c)=K_{c} \otimes I_{N d} \\
\operatorname{Var}(m)=K_{m} \otimes A \\
\operatorname{Var}(e)=K_{q} \otimes I_{N m}
\end{array}
\end{gathered}
$$

where, $y$ is a vector of $\mathrm{N}$ observations corresponding to $\mathrm{N}_{\mathrm{d}}$ animals; $b$ is the vector of fixed effects and $b_{m}$ coefficients of the fixed regression; $\alpha$ is a vector $\mathrm{k}_{\mathrm{a}} \times \mathrm{N}_{\mathrm{D}}$ of random regression coefficients for direct additive genetic effects, with $\mathrm{N}_{\mathrm{D}}$ corresponding to the number of animals in the relationship matrix (5357); $c$ is a vector $\mathrm{k}_{\mathrm{c}} \times \mathrm{N}_{\mathrm{d}}$ of random regression coefficients for permanent environmental effects of the animal; $m$ is a vector $\mathrm{k}_{\mathrm{m}} \times \mathrm{N}_{\mathrm{D}}$ of random regression coefficients for maternal additive genetic effects; $q$ is a vector $\mathrm{k}_{\mathrm{q}} \times \mathrm{N}_{\mathrm{m}}$ of random regression coefficients for maternal permanent environmental effects, with $\mathrm{N}_{\mathrm{m}}$ corresponding to the number of dams with progenies for which observations are available; $e$ is a vector of random errors; $\mathrm{X}, \mathrm{Z}_{1}, \mathrm{Z}_{2}, \mathrm{Z}_{3}$, and $\mathrm{Z}_{4}$ correspond to the incidence matrices of the fixed regression coefficients and fixed effects included in the model, direct additive genetic, animal permanent environmental, maternal additive genetic, and maternal permanent environmental random regression coefficients, respectively; $\mathrm{K}_{\mathrm{a}}, \mathrm{K}_{\mathrm{c}}, \mathrm{K}_{\mathrm{m}}$, and $\mathrm{K}_{\mathrm{q}}$ are (co)variance matrices between random regression coefficients for direct additive genetic, animal permanent environmental, maternal additive genetic, and maternal permanent environmental effects, respectively; $A$ is the numerator relationship matrix; $\mathrm{I}_{\mathrm{Nd}}$ is an identity matrix of $\mathrm{N}_{\mathrm{d}}$ dimension; $\mathrm{I}_{\mathrm{Nm}}$ is an identity matrix of $\mathrm{N}_{\mathrm{m}}$ dimension; $\otimes$ is the Kronecker product; $\mathrm{R}$ is a diagonal matrix of residual variances containing elements estimated by the function described previously, $R=$ diagonal $\left.\mid \sigma_{j}^{2}\right]$. The covariance between direct and maternal additive genetic effects was assumed to be zero.

(Co)variances between direct and maternal additive genetic and animal and maternal permanent environmental random regression coefficients were estimated by the restricted maximum likelihood method using the DXMRR program of the DFREML software (Meyer, 1998a), according to the fitted model.

The different models were compared using the likelihood ratio test (LRT), Akaike information criterion (AIC), and Schwarz's Bayesian information criterion (BIC).

To determine the relative importance of eigenvalues of the random regression coefficient matrix for the effects considered for the explanation of total variation, each eigenvalue is expressed as the percentage of the sum of all eigenvalues. In addition, the (co) 
variance components and genetic parameters estimated along the growth curve with the models that used the functions with the best orders of fit were analyzed and compared to the estimates obtained by single-trait analysis.

\section{RESULTS}

The application of random regression models using Legendre polynomial functions first requires the definition of the most appropriate order of fit for each random effect included in the analysis model. To permit a detailed study, a model fitting only the intercept was first used $\left(k_{\alpha}=1, k_{m}=1, k_{c}=1\right.$, and $k_{q}=1$, i.e., $\mathrm{k}=1111$, in which the four numbers refer to the order of fit for $k_{\alpha}, k_{m}, k_{c}$, and $k_{q}$, respectively), with this model corresponding to a repeatability model (Table 1). As shown in Table 1, model 1 provided the worst values for all criteria used, suggesting that this model is inadequate.

Table 1. Logarithm of the maximum likelihood function ( $\log \mathrm{L}$ ), Akaike information criterion (AIC), Bayesian information criterion (BIC), number of parameters estimated (NP), and likelihood ratio test (LRT) results obtained for the models of random effects associated with weight of Santa Ines sheep from birth to 196 days.

\begin{tabular}{l|c|c|c|c|c|c}
\hline Model $^{1}$ & Log L & AIC $^{2}$ & BIC $^{2}$ & NP & LRT & P \\
\hline $1-111$ & -5209.6 & 10281.7 & 9941.9 & 9 & - & $(2-1) 8291.4$ \\
\hline $2-2222$ & -1063.9 & 2006.2 & 1728.7 & 17 & $<0.0001$ \\
\hline $3-3333$ & -223.1 & 348.6 & 164.6 & 29 & $(3-2) 1681.6$ & $<0.0001$ \\
\hline $4-3343$ & -129.9 & 170.2 & 17 & 33 & $(4-3) 186.4$ & $<0.0001$ \\
\hline $5-3353$ & -96.8 & 114 & 0 & 38 & $(5-4) 66.2$ & $<0.0001$ \\
\hline $6-3363$ & -71.6 & 75.7 & 8.4 & 44 & $(6-5) 50.4$ & $<0.0001$ \\
\hline $7-4363$ & -51.8 & 44 & 7.8 & 48 & $(7-6) 39.6$ & $<0.0001$ \\
\hline $8-5363$ & -41.5 & 33.5 & 36.3 & 53 & $(8-7) 20.6$ & 0.0009 \\
\hline $9-5463$ & -27.5 & 13.5 & 47.4 & 57 & $(9-8) 28$ & $<0.0001$ \\
\hline $10-5563$ & -19.4 & 8.1 & 76.1 & 62 & $(10-9) 16.2$ & 0.006 \\
\hline $11-5564$ & -16.4 & 9.2 & 113.2 & 66 & $(11-10) 6$ & 0.2 \\
\hline $12-5573$ & -8.8 & 0 & 127.4 & 69 & $(12-10) 21.2$ & 0.003 \\
\hline $13-6573$ & -3.4 & 1.2 & 175.2 & 75 & $(13-12) 10.8$ & 0.095 \\
\hline $14-7573$ & 0 & 8.4 & 237 & 82 & $(14-12) 17.6$ & 0.17 \\
\hline
\end{tabular}

${ }^{1}$ Order of fit for direct additive genetic, maternal additive genetic, animal permanent environmental, and maternal permanent environmental effects, respectively. ${ }^{2}$ Values are reported as the deviation from the best value. ${ }^{3}$ Probability value of the LRT.

Next, the orders of fit of the continuous functions were gradually increased in order to permit the determination of the best order necessary to describe variance and covariance structure as a function of time for each random effect. Furthermore, linear $\left(k_{\alpha}=2, k_{m}=2\right.$, $k_{c}=2$, and $k_{q}=2$, corresponding to $\left.\mathrm{k}=2222\right)$ and quadratic $(\mathrm{k}=3333)$ fits for all effects provided higher Log L values $(\mathrm{P}<0.01, \mathrm{LRT})$ and lower AIC and BIC values, indicating that $\mathrm{k}=2222$ was superior to the fit in which variances were maintained constant (Table 1). However, the Log L, AIC, and BIC values were lower than those obtained with higher order of fit models, suggesting that these models provide simple fits to represent changes in variances as a function of time.

According to the Log $\mathrm{L}$ results, the highest orders for the effects analyzed yielded the highest values, suggesting that the most parameterized model (model 14 consisting of 82 parameters to be estimated), with $\mathrm{k}=7573$ for direct additive genetic, maternal additive genetic, animal permanent environmental, and maternal permanent environmental effects, 
respectively, provided the best fit. However, application of the LRT showed that orders $k_{\alpha}=6$ and $k_{\alpha}=7$ for direct additive genetic effects did not differ significantly from $k_{\alpha}=5(\mathrm{P}>0.05)$, indicating that higher orders for this effect do not improve model fit.

Analysis of the results using the AIC showed that a function with orders $\mathrm{k}=5573$ (69 parameters) was sufficient to fit (co)variances along the growth trajectory. Thus, according to the AIC and LRT, this model was the most adequate to model genetic and permanent environmental effects in the population studied.

However, based on the BIC, which imposes a more rigorous penalty factor than the AIC as a function of the number of parameters estimated, the model using functions with orders $\mathrm{k}=353$ (38 parameters) for direct and maternal additive genetic effects and animal and maternal permanent environmental effects, respectively, was sufficient to model changes in variances with age.

The estimates of (co)variances and correlations between random regression coefficients obtained with the models whose function used $\mathrm{k}=3353$ and $\mathrm{k}=5573$ are shown in Tables 2 and 3 , respectively.

The intercept was positively correlated with the linear coefficient and negatively correlated with the other coefficients. The correlation between regression coefficients ranged from low to high, with the highest correlations being obtained with model $\mathrm{k}=3353$ for direct and maternal additive genetic effects and maternal permanent environmental effects.

\begin{tabular}{|c|c|c|c|c|c|}
\hline 1 & 2 & 3 & 4 & 5 & Eigenvalue (\%) \\
\hline \multicolumn{6}{|c|}{ Direct additive genetic effect $\left(k_{a}=3\right)$} \\
\hline 2.607 & 0.99 & -0.87 & & & 99.47 \\
\hline 0.90 & 0.312 & -0.91 & & & 0.53 \\
\hline-0.352 & -0.130 & 0.062 & & & 0.00 \\
\hline \multicolumn{6}{|c|}{ Maternal additive genetic effect $\left(k_{m}=3\right)$} \\
\hline 2.340 & 0.93 & -0.91 & & & 0.98 \\
\hline 0.717 & 0.254 & -0.76 & & & 1.32 \\
\hline-0.307 & -0.085 & 0.048 & & & 0.20 \\
\hline \multicolumn{6}{|c|}{ Permanent environmental effect of animal $\left(k_{c}=5\right)$} \\
\hline 8.894 & 0.83 & -0.52 & 0.061 & -0.17 & 91.89 \\
\hline 3.217 & 1.681 & -0.21 & -0.23 & -0.07 & 5.20 \\
\hline-0.945 & -0.170 & 0.360 & 0.16 & -0.32 & 2.16 \\
\hline 0.062 & -0.102 & 0.032 & 0.120 & 0.07 & 0.73 \\
\hline-0.122 & -0.021 & -0.046 & 0.006 & 0.058 & 0.02 \\
\hline \multicolumn{6}{|c|}{ Maternal permanent environmental effect $\left(k_{q}=3\right)$} \\
\hline 0.752 & 0.66 & -0.99 & & & 98.84 \\
\hline 0.072 & 0.016 & -0.69 & & & 1.05 \\
\hline-0.267 & -0.027 & 0.096 & & & 0.11 \\
\hline
\end{tabular}

The estimates of variances from birth to 196 days of age for each random effect obtained with the models suggested by the AIC and BIC are shown in Figure 1. The estimates of direct additive genetic variance tended to increase from birth to 196 days of age, with the observation of small differences in the estimates obtained with the fitted functions and those obtained by single-trait analysis. Model $\mathrm{k}=3353$ resulted in a smoother curve, whereas the curve obtained with model $\mathrm{k}=5573$ presented slight oscillations along its trajectory, possibly because of the larger number of parameters permitting greater flexibility. Both models 
provided direct additive genetic variance estimates that were consistent with those obtained with the traditional model.

Table 3. Estimates of variances (diagonal), covariances (below the diagonal), and correlations (above the diagonal) between random regression coefficients and eigenvalues associated with the coefficient matrix obtained with model $\mathrm{k}=5573$ for Santa Ines sheep.

\begin{tabular}{|c|c|c|c|c|c|c|c|}
\hline 1 & 2 & 3 & 4 & 5 & 6 & 7 & Eigenvalue (\%) \\
\hline \multicolumn{8}{|c|}{ Direct additive genetic effect $\left(k_{a}=5\right)$} \\
\hline 2.777 & 0.97 & -0.41 & 0.79 & -0.57 & & & 98.43 \\
\hline 0.808 & 0.247 & -0.54 & 0.77 & -0.44 & & & 1.10 \\
\hline-0.0964 & -0.037 & 0.019 & -0.60 & -0.16 & & & 0.29 \\
\hline 0.157 & 0.046 & -0.010 & 0.014 & -0.09 & & & 0.19 \\
\hline-0.147 & -0.034 & -0.003 & -0.001 & 0.023 & & & 0.00 \\
\hline \multicolumn{8}{|c|}{ Maternal additive genetic effect $\left(k_{m}=5\right)$} \\
\hline 2.391 & 0.80 & -0.94 & 0.62 & -0.07 & & & 96.06 \\
\hline 0.571 & 0.211 & -0.89 & 0.16 & 0.33 & & & 3.31 \\
\hline-0.250 & -0.070 & 0.029 & -0.58 & -0.19 & & & 0.52 \\
\hline 0.152 & 0.011 & -0.015 & 0.025 & -0.19 & & & 0.11 \\
\hline-0.015 & 0.019 & -0.004 & -0.003 & 0.015 & & & 0.00 \\
\hline \multicolumn{8}{|c|}{ Permanent environmental effect of animal $\left(k_{c}=7\right)$} \\
\hline 8.891 & 0.83 & -0.52 & -0.007 & -0.05 & -0.15 & -0.22 & 90.47 \\
\hline 3.441 & 1.905 & -0.17 & -0.13 & -0.22 & -0.30 & 0.12 & 5.98 \\
\hline-1.016 & -0.157 & 0.428 & 0.31 & -0.42 & -0.21 & 0.05 & 2.25 \\
\hline-0.007 & -0.070 & 0.079 & 0.143 & 0.02 & $\begin{array}{c}-0.39 \\
\end{array}$ & -0.16 & 0.64 \\
\hline-0.040 & -0.077 & -0.069 & 0.002 & 0.061 & 0.59 & 0.10 & 0.57 \\
\hline-0.111 & -0.101 & -0.034 & -0.036 & 0.036 & 0.060 & 0.05 & 0.08 \\
\hline-0.072 & 0.017 & 0.003 & -0.006 & 0.002 & 0.001 & 0.011 & 0.00 \\
\hline \multicolumn{8}{|c|}{ Maternal permanent environmental effect $\left(k_{q}=3\right)$} \\
\hline 0.772 & 0.80 & -0.99 & & & & & 98.60 \\
\hline 0.131 & 0.034 & -0.82 & & & & & 1.40 \\
\hline-0.228 & -0.040 & 0.067 & & & & & 0.00 \\
\hline
\end{tabular}
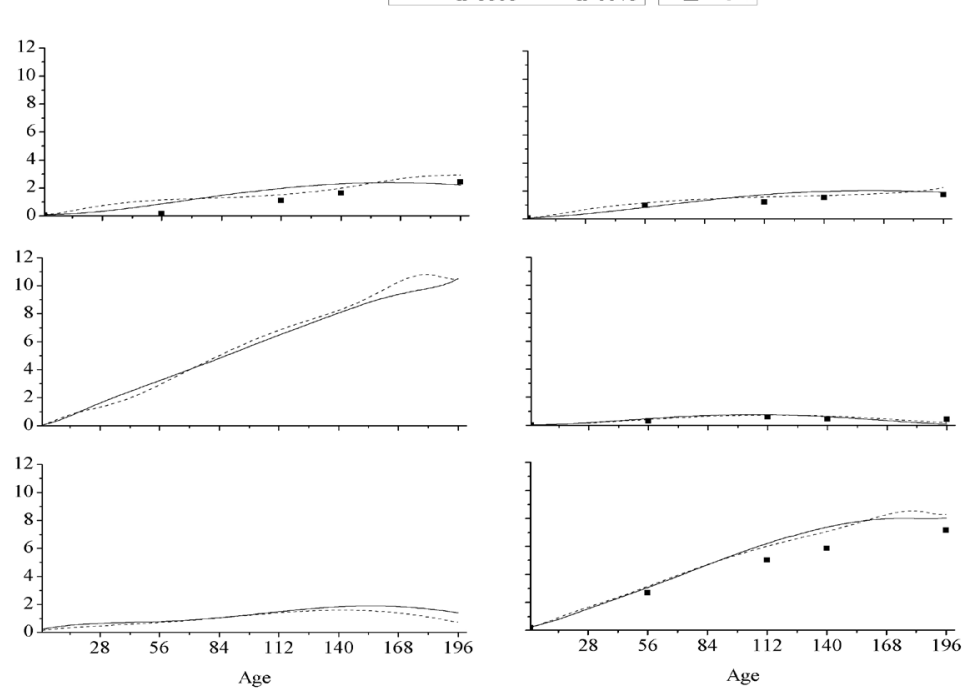

Figure 1. Estimates of direct genetic (top left), maternal genetic (top right), animal permanent environmental (middle left), maternal permanent environmental (middle right), residual (bottom left), and phenotypic (bottom right), divided by 2 , variance components obtained with models $\mathrm{k}=3353, \mathrm{k}=5573$, and single-trait analysis (STA) for Santa Ines sheep from birth to 196 days of age. 
Maternal additive genetic variance estimates also increased, but at a slightly lower magnitude than direct additive genetic variance (Figure 1). Maternal additive genetic variances estimated by the two models were similar and consistent with the estimates obtained by singletrait analysis. However, estimates obtained with model $\mathrm{k}=5573$ presented slight oscillations, with a minor increase at the end of the curve.

The estimates of animal permanent environmental variance increased from birth to 196 days of age (Figure 1). In this respect, the model including $k_{c}=7$ resulted in a more marked increase at the end of the curve when compared to the model including $k_{c}=5$. Considering the same age range as studied here, Fischer et al. (2004) also estimated increasing animal permanent environmental variances, similar to the findings reported by Sarmento et al. (2006a).

For maternal permanent environment, similar variance estimates were obtained with the two models (Figure 1), as expected, since the models employ the same orders for this effect, $k_{q}=3$. The estimated variances were low and similar to those obtained by single-trait analysis.

Phenotypic variance estimates increased with age up to approximately 150 days, followed by a slight deceleration in growth (Figure 1). The phenotypic variances estimated by the two models were similar and close to those estimated by analyses that consider each weight as one trait. Residual variance showed a behavior similar to that of phenotypic variance but at a lower magnitude. Residual variance estimated with model $\mathrm{k}=3353$ increased up to approximately 150 days of age, whereas that estimated with model $\mathrm{k}=5573$ tended to be slightly lower, especially after 140 days of age, as expected, because of the larger number of parameters to be estimated.

Direct heritabilities estimated with models $\mathrm{k}=3353$ and $\mathrm{k}=5573$ differed slightly at the beginning of the curve. As shown in Figure 2A, estimates obtained with model k $=3353$ decreased from birth (0.16) to 15 days (0.09), then increased up to approximately 112 days (0.16), and decreased slowly up to 196 days of age (0.14). Heritability estimates obtained with model $\mathrm{k}=5573$ decreased from the beginning, increased from 10 (close to 0.18 ) to 28 days $(0.21)$, followed by a decline to 112 days $(0.12)$, and then increased again up to 196 days of age (0.18). The function with $\mathrm{k}=3353$ yielded direct heritability estimates closer to those obtained by single-trait analysis during the period preceding weaning when compared to function $\mathrm{k}=5573$. After 112 days of age, the estimates obtained with function $\mathrm{k}=5573$ were similar to those obtained with the traditional models, although the differences between $\mathrm{k}=$ 3353 and $\mathrm{k}=5573$ were small.

Maternal heritability estimates obtained with the two models in the present study differed, especially during the period preceding weaning. As shown in Figure 2B, maternal heritability estimated with model $\mathrm{k}=3353$ tended to decrease from birth $(0.16)$ to 15 days of age (0.11), followed by an increase up to 84 days (0.14), and then tended to decrease until the end of the growth period studied (0.11). However, maternal heritability estimated with model $\mathrm{k}=5573$ tended to decreased from the beginning to 10 days, with increased to 28 days of age $(0.20)$, followed by a decreasing trajectory and a slight increase at 196 days $(0.13)$. Figure 2B also shows that model $\mathrm{k}=5573$ provided maternal heritability estimates closer to those obtained by single-trait analysis before 112 days of age, with practically no differences after this age.

Animal permanent environmental variance as a proportion of phenotypic variance estimated with models $\mathrm{k}=3353$ and $\mathrm{k}=5573$ was similar (Figure 2C). The proportions of estimated variances increased with age, with the magnitude of the increase being greater at the beginning of the growth period. Model $\mathrm{k}=3353$ provided higher estimates from 28 to 56 days 


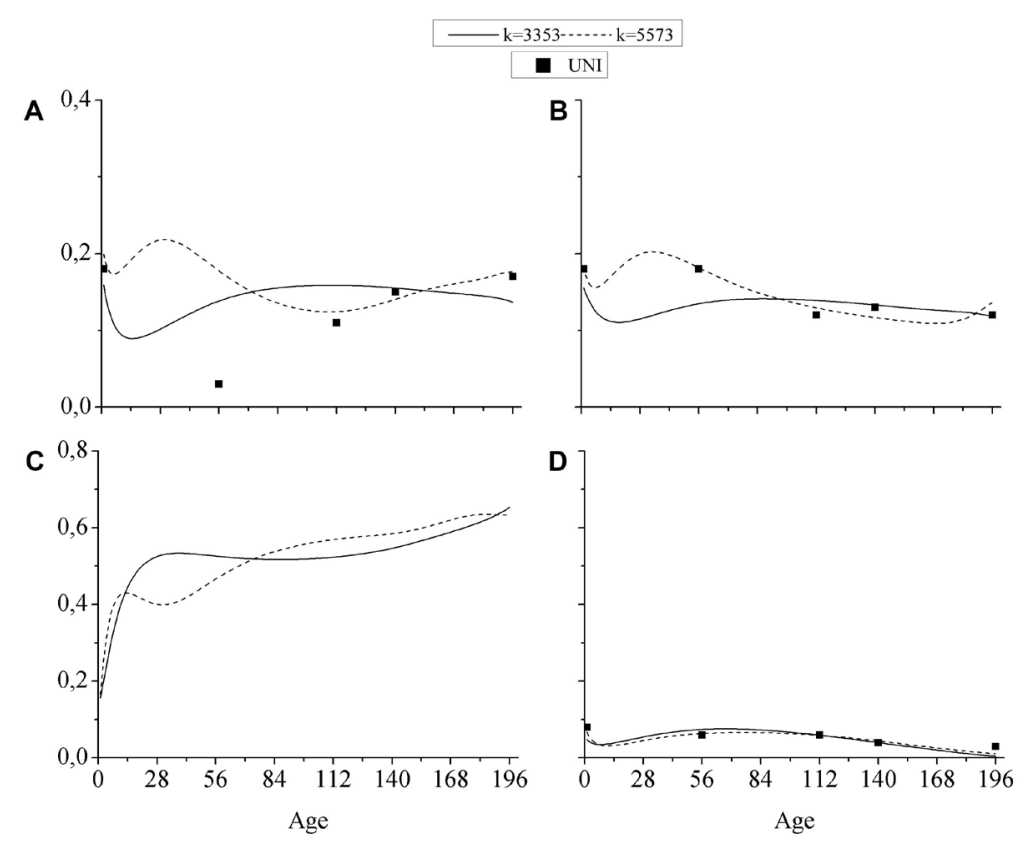

Figure 2. Estimates of direct $\left(\mathrm{h}^{2}\right)$ and maternal $\left(\mathrm{m}^{2}\right)$ heritability, and variance components for animal $\left(\mathrm{c}^{2}\right)$ and maternal $\left(\mathrm{q}^{2}\right)$ permanent environmental effects as a proportion of phenotypic variance obtained with models $\mathrm{k}=$ $3353, \mathrm{k}=5573$, and by single-trait analysis (STA) for Santa Ines sheep from birth to 196 days of age.

of age, followed by lower values thereafter, although the values were closer to those obtained with model $\mathrm{k}=5573$.

Maternal permanent environmental variance estimates as a proportion of phenotypic variance (Figure 2D) did not differ between the two models, except for the beginning of the curve when slightly higher values were obtained with model $\mathrm{k}=5573$. The estimates were low (all lower than 0.1), but showed a behavior similar to that obtained by single-trait analysis. Estimates presenting an opposite tendency have been reported by Fischer et al. (2004), i.e., the contribution of this effect decreased from 50 to 200 days of age and was higher than maternal heritability during this period.

Small differences were observed in the estimates of direct and maternal genetic correlations. An increase in the order of fit from three to five resulted in the occurrence of some surface undulations for direct and maternal genetic correlations (Figure 3). Direct genetic correlations ranged from 0.38 to near one. In contrast, maternal genetic correlations ranged from 0.60 to 1.0 .

The course of animal permanent environmental correlations also differed between the two models (Figure 3). Model $\mathrm{k}=3353$ described a more planer surface of correlations than model $k=5573$. As shown in Figure 3, an increase in the order of fit from five to seven resulted in the occurrence of undulations in the correlations and in an increase of correlations between ages at the extremities of the curve, which is in contrast to the expected decline in these correlations. The estimated correlations ranged from 0.38 to 0.98 and from 0.34 to 0.99 for models $\mathrm{k}=3353$ and $\mathrm{k}=5573$, respectively. 

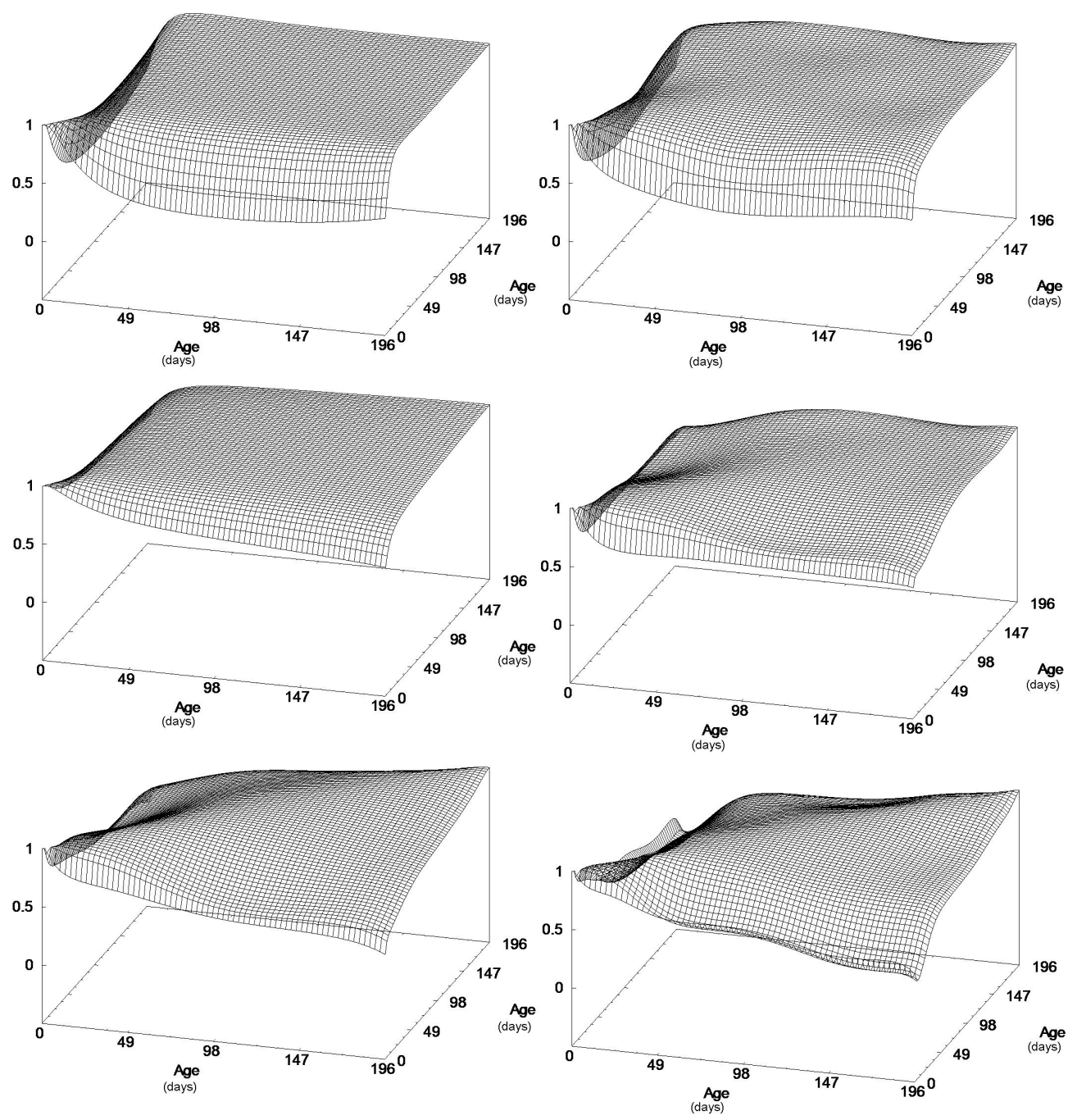

Figure 3. Direct genetic (top), maternal genetic (middle), and animal permanent environmental (bottom) correlations estimated with models k = 3353 (left) and k = 5573 (right) for Santa Ines sheep from birth to 196 days of age.

Practically no differences in the estimated maternal permanent environmental correlations were observed between the two models (data not shown). This finding was expected since the same order of fit, $k_{q}=3$, was used in the two models for this effect.

\section{DISCUSSION}

The estimates of constant variances, with adjust model 1, do not fit the growth curve of the sheep studied. Similar results have been reported by Meyer (1998b) and Sakaguti (2000) for beef cattle (Table 1). 
Lewis and Brotherstone (2002) observed that a model with $\mathrm{k}=553$ was sufficient to model variances due to direct additive genetic, animal permanent environmental, and maternal permanent environmental effects, respectively. Fischer et al. (2004) fitted less parameterized models, with three being the highest order for all random effects. The best fit was obtained with the model using $\mathrm{k}=3233$ for direct and maternal additive genetic effects and animal and maternal permanent environmental effects, respectively. Sarmento et al. (2006a), comparing orders of three and four for direct and maternal additive genetic effects and animal permanent environmental effects, observed that the higher order provided the best fit. According to the present results and those reported in the literature, it is clear that the use of the same order of fit for all random effects may not be a good strategy of analysis.

Positive correlations between the intercept and linear coefficient have also been reported by Fischer et al. (2004). The intercept explained the highest proportion of variance for all random effects included in the model. A larger number of eigenvalues associated with the matrix of coefficients close to zero were observed when the more parameterized model was used. This finding might be explained by increased multicollinearity due to the increase in the order of fit of the function employed, suggesting a reduction of dimensionality.

According to Legarra et al. (2004), a perfect model fit increases computational requirements (memory and processing capacity) and susceptibility to numerical errors. Thus, more parsimonious models are preferable. However, selection of the polynomial order to be used is not an easy task and eigenvalues may be a useful tool for this purpose (Foulley and Robert-Granié, 2002). Analysis of the data (Tables 2 and 3) showed that the model employing higher orders, $\mathrm{k}=5573$, provided a larger number of eigenvalues close to zero, suggesting that higher orders poorly explain total variance. Thus, the dimensionality of the random effects studied may be reduced without the loss of information as indicated by the BIC. However, Legarra et al. (2004) highlighted the fact that a reduction of dimensionality due to the elimination of eigenvalues close to zero is not indicated in all cases, since adoption of this criterion may result in simplistic or inadequate modeling. We therefore chose to analyze the variance components estimated by the different models and the resulting genetic parameters.

Increasing estimates of direct additive genetic variances along the growth trajectory have been reported by Lewis and Brotherstone (2002), Fischer et al. (2004), and Sarmento et al. (2006a). These authors described smooth courses without sudden changes along the trajectory, similar to that observed for the estimates obtained with model $\mathrm{k}=3353$. In beef cattle, Meyer (2001) and Albuquerque and Meyer (2001) described increasing estimates along the period studied, with a slight tendency towards a decline at the end of the growth curve.

Fischer et al. (2004) reported practically constant maternal additive genetic variances up to 200 days of age. In contrast, Sarmento et al. (2006a) described a growing trajectory up to approximately 140 days of age, which tended to decrease slightly thereafter. In beef cattle, Meyer (2001) estimated increasing maternal additive genetic variances from birth to 250 days of age. In contrast, Albuquerque and Meyer (2001) reported an increase in maternal additive genetic variance estimates up to about 200 days of age, followed by a tendency towards a decline until 600 days of age.

Increasing direct heritabilities along the growth trajectory have been reported by Lewis and Brotherstone (2002), with heritability ranging from 0.15 at 15 days to 0.38 at 150 days, by Fischer et al. (2004) who obtained estimates ranging from 0.15 at 50 days to 0.20 at 200 days, and by Sarmento et al. (2006a) who obtained estimates ranging from practically 0 
at birth to 0.28 at 196 days of age. However, using traditional methods (single- or two-trait animal model analysis), Sousa et al. (1999) estimated decreasing heritability from birth (0.12) to 112 days of age (0.03) and increasing heritability from 112 to 196 days (0.07). A similar trend has been reported by Sarmento et al. (2006b), except at birth when heritability was higher (0.23). Increasing heritabilities with age have been reported in a study by Snyman et al. (1995), in which estimates increased from birth (0.22) to 6 months of age (0.47).

Sarmento et al. (2006a) estimated increasing heritabilities from birth to 56 days of age, followed by a decline thereafter. In contrast, Fischer et al. (2004) reported practically constant heritabilities from 50 to 200 days of age, with all estimates being lower than 0.1 .

Maternal heritability estimates obtained with model $\mathrm{k}=5573$ tended to increase after birth, a trend also described by model $\mathrm{k}=3353$ but at a lower magnitude. However, analyzing maternal heritability estimated with model $\mathrm{k}=5573$, a greater contribution of the dam to her offspring (maternal heritability higher than direct heritability) occurred from 56 to 120 days, i.e., direct heritability estimates were higher than estimates for maternal effect during the initial phase of growth, a finding that is not biologically expected. According to the maternal heritability estimates obtained with model $\mathrm{k}=3353$, the maximum contribution of the dam to the phenotype of her offspring occurred up to 56 days, which is biologically acceptable since the lamb is completely dependent on maternal care, especially milk produced by the mother, during the first days of life. In view of the biological factor related to direct and maternal additive genetic effects, model $\mathrm{k}=3353$ provided more consistent variance and heritability estimates. A greater maternal contribution until 56 days of age has been described by Sarmento et al. (2006a). However, some investigators always reported lower maternal heritabilities when compared to direct heritabilities in meat sheep, such as Snyman et al. (1995) using traditional models and Fischer et al. (2004) using random regression.

After 56 days of age, the direct heritability estimates were higher than maternal heritabilities. However, a greater decline in maternal heritability was expected when reaching 196 days of age. The persistence of the contribution of maternal effects to the offspring at advanced ages in meat sheep has been reported by Snyman et al. (1995), Sousa et al. (1999), and Sarmento et al. (2006b). The present result may be due to the management system adopted in the flocks in which, in addition to maintaining ewes with lambs at foot, the lambs may not be effectively weaned at 112 days of age. Another aspect related to this result is the lack of appropriate feeding management during the initial growth phase of the lambs, a fact that may intensify and prolong their dependence on maternal care. Another hypothesis that could be raised is related to the structure of the data in which the number of observations markedly declined after weaning, a fact that may impair correct partition of total variance into its direct and maternal additive genetic components.

Similar results for animal permanent environmental variance as a proportion of phenotypic variance estimated have been reported by Sarmento et al. (2006a) for Santa Ines sheep. A growing trend for this effect has also been observed by Fischer et al. (2004), although the increase was milder. Meyer (2001) described a similar behavior for beef cattle.

In conclusion, a polynomial Legendre function of order three, three, five, and three for direct and maternal genetic effects and animal and maternal permanent environmental effects, respectively, should be used to describe changes in (co)variances along the growth curve of the Santa Ines sheep studied. The heritability estimates indicate that selection for weight will result in small genetic gains. Selection for any age will result in a correlated response, in the same direction, at the other ages, although genetic gains are small. 


\section{Conflicts of interest}

The authors declare no conflict of interest.

\section{ACKNOWLEDGMENTS}

We thank Conselho Nacional de Desenvolvimento Científico e Tecnológico (CNPq), Coordenação de Aperfeiçoamento de Pessoal de Nível Superior (CAPES), and Paraíba State Company of Agricultural Research (EMEPA-PB) and the Brazilian Agricultural Research Company (EMBRAPA Caprinos and EMBRAPA Tabuleiros Costeiros), in relation to data used.

\section{REFERENCES}

Albuquerque LG and Meyer K (2001). Estimates of covariance functions for growth from birth to 630 days of age in Nelore cattle. J. Anim. Sci. 79: 2776-2789.

Fischer TM, Van der Werf JHJ, Banks RG and Ball AJ (2004). Description of lamb growth using random regression on field data. Livest. Prod. Sci. 89: 175-185.

Foulley JL and Robert-Granié C (2002). Heteroskedastic random coefficient models. Proceedings of the 7th World Congress on Genetics Applied to Livestock Production, Montpellier, France.

Henderson CR Jr (1982). Analysis of covariance in the mixed model: higher-level, nonhomogeneous, and random regressions. Biometrics 38: 623-640. http://dx.doi.org/10.2307/2530044

Legarra A, Misztal I and Bertrand JK (2004). Constructing covariance functions for random regression models for growth in Gelbvieh beef cattle. J. Anim. Sci. 82: 1564-1571.

Lewis RM and Brotherstone S (2002). A genetic evaluation of growth in sheep using random regression techniques. Anim. Sci. 74: 63-70.

Meyer K (1998a). "DXMRR”-A program to estimate covariance functions for longitudinal data by Restricted Maximum Likelihood. Proceedings of the 6th World Congress on Genetics Applied to Livestock Production, Armidale, Australia, 465-466.

Meyer K (1998b). Estimating covariance functions for longitudinal data using a random regression model. Genet. Sel. Evol. 30: 221-240. http://dx.doi.org/10.1186/1297-9686-30-3-221

Meyer K (2001). Estimates of direct and maternal covariance functions for growth of Australian beef calves from birth to weaning. Genet. Sel. Evol. 33: 487-514. http://dx.doi.org/10.1186/1297-9686-33-5-487

Meyer K (2005). Estimates of genetic covariance functions for growth of Angus cattle. J. Anim. Breed. Genet. 122: 73-85. http://dx.doi.org/10.1111/j.1439-0388.2005.00503.x

Molina A, Menéndez-Buxadera A, Valera M and Serradilla JM (2007). Random regression model of growth during the first three months of age in Spanish Merino sheep. J. Anim. Sci. 85: 2830-2839. http://dx.doi.org/10.2527/jas.2006-647

Sakaguti ES (2000). Funções de covariância e modelos de regressão aleatória na avaliação genética do crescimento de bovinos jovens da raça Tabapuã. Doctoral thesis, Universidade Federal de Viçosa, Viçosa.

Sarmento JLR, Torres RA, Pereira CS, Sousa WH, et al. (2006a). Avaliação genética de características de crescimento de ovinos Santa Inês utilizando modelos de regressão aleatória. Arq. Bras. Med. Vet. Zootec 58: 68-77. http://dx.doi. org/10.1590/S0102-09352006000100011

Sarmento JLR, Torres RA, Sousa WH, Pereira CS, et al. (2006b). Estimação de parâmetros genéticos para características de crescimento de ovinos Santa Inês utilizando modelos uni e multicaracterísticas. Arq. Bras. Med. Vet. Zootec 58: 581-589. http://dx.doi.org/10.1590/S0102-09352006000400021

Sarmento JLR, Torres RA, Lôbo RNB, Albuquerque LD, et al. (2010). Modelos de regressão aleatória na avaliação genética do crescimento de ovinos da raça Santa Inês. Rev. Bras. Zootec. 39: 1723-1732.http://dx.doi.org/10.1590/S1516-35982010000800014

Sarmento JLR, Torres RA, Sousa WH, Albuquerque LG, et al. (2011). Modeling average growth curve in Santa Ines sheep using random regression models. Rev. Bras. Zootec. 40: 314-322.

Snyman MA, Erasmus GJ, Van Wyk JB and Olivier JJ (1995). Direct and maternal (co)variance components and heritability estimates for body weight different ages and fleece traits in Afrino sheep. Livest. Prod. Sci. 44: 229-235. http://dx.doi.org/10.1016/0301-6226(95)00071-2

Sousa WH, Pereira CS, Bergmann JAG and Silva FD (1999). Estimativas de componentes de (co)variância e herdabilidade direta e materna de pesos corporais em ovinos da raça Santa Inês. Rev. Bras. Zootec. 28: 1252-1262. http://dx.doi. org $/ 10.1590 / \mathrm{S} 1516-35981999000600012$ 